\title{
CENTRAL RETINAL ARTERY OCCUSION FOLLOWING BLUNT TRAUMA
}

\section{Sarita Gonsalves ${ }^{1}$, Nayana Prabhu², Srinivas M. Ganagi ${ }^{3}$, Vishnu Prabhu ${ }^{4}$, Vikram Shetty ${ }^{5}$}

\section{HOW TO CITE THIS ARTICLE:}

Sarita Gonsalves, Nayana Prabhu, Srinivas M. Ganagi, Vishnu Prabhu, Vikram Shetty. "Central Retinal Artery Occusion following Blunt Trauma". Journal of Evolution of Medical and Dental Sciences 2014; Vol. 3, Issue 67, December 04; Page: 14553-14557, DOI: 10.14260/jemds/2014/3954

\begin{abstract}
Central retinal artery occlusion following blunt trauma a 19-year-old patient presented with complaints of severe loss of vision in the right eye following a high pressure compressor gas injury of 1 day duration. External ocular examination revealed ecchymosis in the right eye and relative afferent pupillary defect. Fundus examination showed white- out retina and a cherry red spot at the macula in the right. A clinical diagnosis of right central retinal arterial obstruction (CRAO) was made. CRAO in young is a rare disease usually found in patients with cardiac embolic diseases, coagulopathies or systemic vascular inflammations and rarely following trauma. Despite active intervention the visual loss persisted. Hence the case report.
\end{abstract}

INTRODUCTION: A 19 year old male presented with history of trauma to the right eye at his work place with a high pressure gas compressor at his work place of 1 day duration. He complained of sudden loss of vision in the right eye. He also complained of redness, watering and pain on eye movements. He did not complain of flashes of light or floaters in the affected eye.

There was no history of headache, vomiting, loss of consciousness or nasal bleed.

On examination the visual acuity in the right eye was perception of light. Projection of rays was absent in the superior and inferior quadrants and visual acuity in the left eye was 6/6.

Examination of the right eye showed ecchymosis in the lids, sub conjunctival hemorrhage, congestion. (Fig. 1) There was a conjunctival laceration from 9-1 clock hours (Fig. 2) with a relative afferent pupillary defect (Grade 3). Fundus examination of the right eye - Media was clear. Disc appeared hyperemic; margins were well defined with a flame shaped hemorrhage at the disc. There was arteriolar attenuation and venous dilatation. Pale whitish edematous retinal area noted in all quadrants with significant edema concentrated over posterior pole. Small area of normal retina noted in nasal and temporal aspect of disc. Vascularity around the macula was obscured and a cherry red spot was seen at the macula (Fig. 3). The intraocular pressure by applanation tonometry was $24 \mathrm{mmHg}$ in the right eye and $14 \mathrm{nn} \mathrm{Hg}$ in the left eye. The examination of the anterior and posterior segments of the left eye was within normal limits. A diagnosis of traumatic central retinal occlusion was made.

Routine blood investigations and coagulation profile was done which was normal. CT orbit showed extensive areas of air pockets in extraconal and intraconal area along with extension into the optic canal and suprasellar areas. (Fig. 4) (Fig. 5).

Treatment was initiated with ocular massaging, paracentesis, vasodilators-nitrates, topical antibiotic-NSAID combination, topical timolol malleate BD and oral acetazolamide 500mg BD. Oral steroids were started $1 \mathrm{mg} / \mathrm{Kg}$ per body weight.

Vision improved to hand movements on the first day after treatment. 4 weeks later the vision improved to counting fingers close to face and 4/60 in the temporal quadrant. Rapd remained in the right eye, the fundus showed a paler disc with retinal whitening and a cherry red spot at the macula. 


\section{CASE REPORT}

DISCUSSION: Central retinal artery occlusion commonly occurs in the elderly. It constitutes 1 in 10, 000 outpatient visits. 2/being bilateral. More common in individuals above 60 years with co existent diabetes or hypertension. The most common cause being atheromatous emboli from the internal carotid artery. ${ }^{1}$ In older patients giant cell arteritis has to be ruled out. In these patients' symptoms of headache, fever, anorexia, loss of weight, jaw claudication should be asked for. The other causes being cardiovascular disorders, carotid dissection. The incidence of CRAO in young is around 8/. Coagulopathies, hemoglobinopathies, autoimmune diseases are common in these patients. Smoking could be a contributory factor.

Trauma is also reported to cause CRAO although not many cases have been reported. The cause of crao secondary to trauma may be due to soft tissue edema, bone impingement, hematoma compressing on the retinal vessels. This may in turn cause damage to the arterial endothelium exposing the collagen causing platelet aggregation and thrombus formation which in turn causes CRAO. Vasospasm secondary to direct trauma could be another cause. The patient usually presents with sudden painless loss of vision, with prior history of amaurosis fugax ranging from few minutes to few hours may be present.

The visual acuity may range from hand movements to perception of light. Patients with ophthalmic artery occlusion present with absent light perception. Early intervention in the form of paracentesis, anticoagulants, topical and oral intra ocular pressure lowering agents, vasodilators, thrombolytics, hyperbaric oxygen has been advocated to prevent irreversible visual loss. However studies have shown the final visual outcome to be not more than 20/40 despite early intervention. However in our patient despite immediate intervention the sequelae were irreversible. The incidence of stroke is said to be higher in patients with CRAO. ${ }^{2}$ Life expectancy is 5.5 years compared to people without CRAO which is 15.4 years. $^{3}$

\section{CONCLUSION:}

- CRAO is potential complication after blunt trauma.

- Paracentesis should be attempted along with other modes of treatment of CRAO.

- Traumatic optic neuropathy to be kept in consideration.

\section{REFERENCES:}

1. Chawla JC: Traumatic central retinal artery occlusion. Trans Ophthalmol Soc UK 1972; 92: 777-784.

2. Prognosis and prognostic factors of retinal infarction, GJ Hankey BMJ 1991. March 2; 302: 499504.

3. ACP journal club commentary, Feinberg A W, july-august 1991, 24-115. 
Fig. 1: Showing ecchymosis and lid edema of both upper and lower lids.

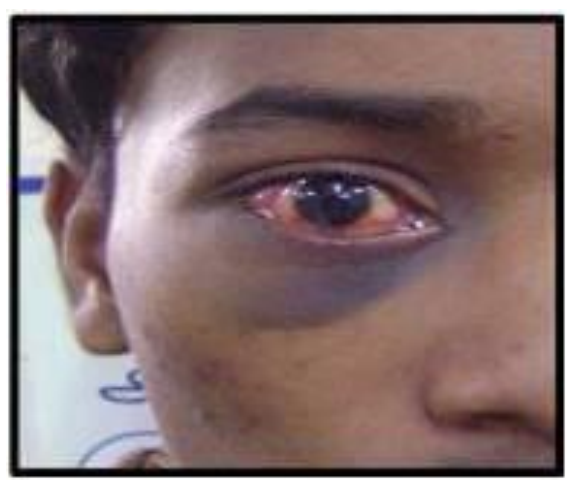

\section{Fig. 1}

Fig. 2: Shows conjunctival laceration and sub conjunctival hemmorrhage.

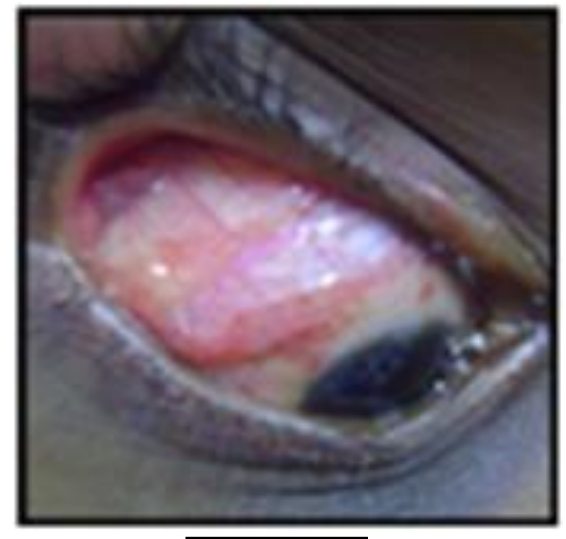

Fig. 2

Fig. 3: Showing hyperemic disc, with flame shaped hemmorrhage at the disc and pale whitish edematous retina in all quadrants with significant edema concentrated over posterior pole.

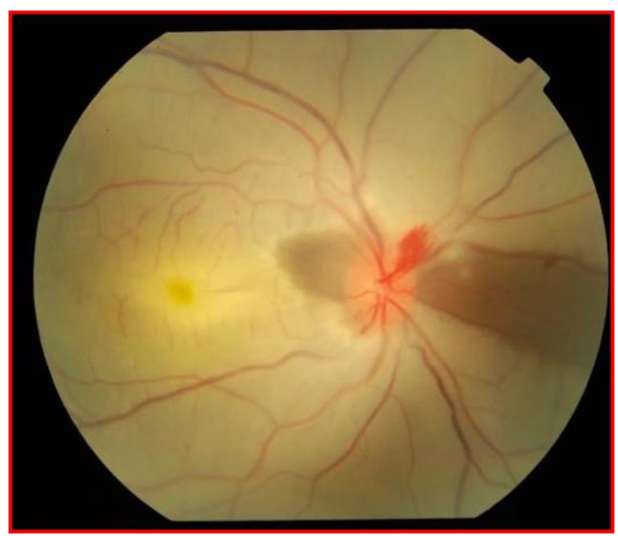

\section{Fig. 3}




\section{CASE REPORT}

Fig. 4: CT orbit showing extensive areas of air pockets in extraconal and intraconal area along with extension into the optic canal and suprasellar areas.

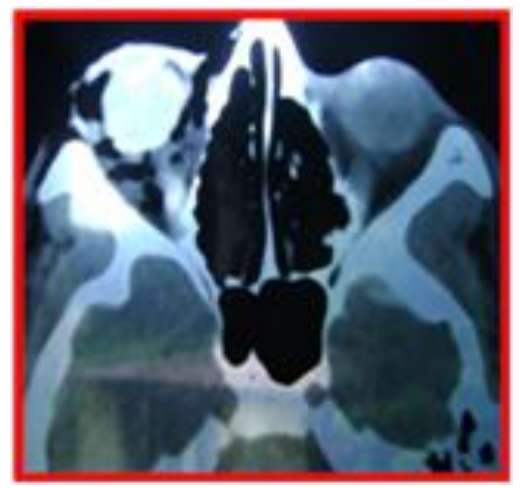

\section{Fig. 4}

Fig. 5: CT orbit showing extensive areas of air pockets in extraconal and intraconal area along with extension into the optic canal and suprasellar areas.

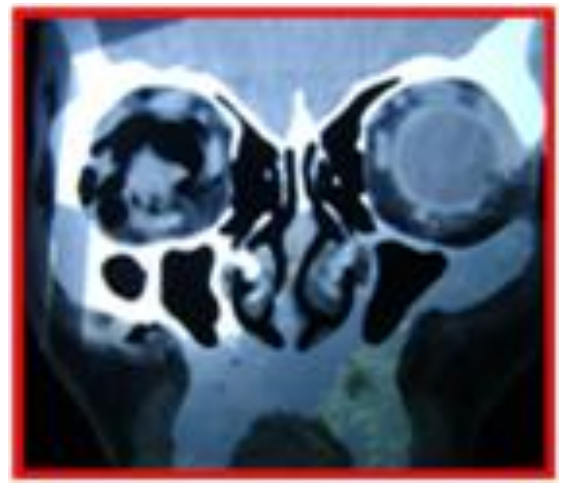

\section{Fig. 5}

Fig. 6: Showing pale whitish retina in all quadrants with a cherry red spot at the macula.

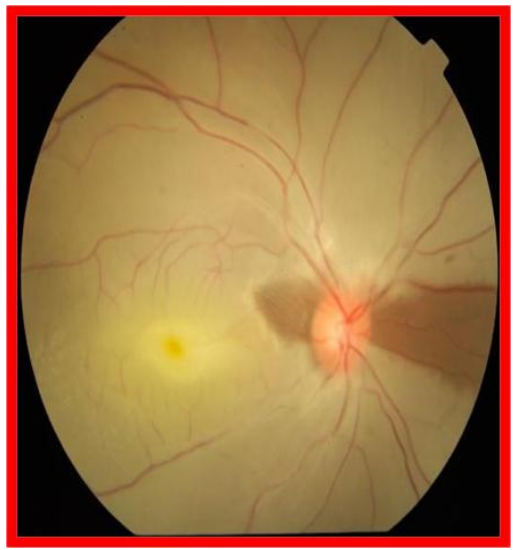

Fig. 6 


\section{AUTHORS:}

1. Sarita Gonsalves

2. Nayana Prabhu

3. Srinivas M. Ganagi

4. Vishnu Prabhu

5. Vikram Shetty

\section{PARTICULARS OF CONTRIBUTORS:}

1. Assistant Professor, Department of Ophthalmology, Srinivas Medical College, Mangalore.

2. Associate Professor, Department of Obstetrics and Gynaecology, Srinivas Medical College, Mangalore.

3. Associate Professor, Department of Ophthalmology, Srinivas Medical College, Mangalore.

4. Professor and HOD, Department of Ophthalmology, Srinivas Medical College, Mangalore.
5. Assistant Professor, Department of Pharmacology, Srinivas Medical College, Mangalore.

\section{NAME ADDRESS EMAIL ID OF THE CORRESPONDING AUTHOR:}

Dr. Vishnu Prabhu,

Professor and HOD,

Department of Ophthalmology,

Srinivas Medical College, Mangalore.

Email: nayana.nethralaya@gmail.com

Date of Submission: 18/11/2014.

Date of Peer Review: 19/11/2014.

Date of Acceptance: 28/11/2014.

Date of Publishing: 04/12/2014. 